\title{
MECHANICAL TESTS APPLIED TO STRUCTURAL HEALTH MONITORING: AN OVERVIEW OF PREVIOUS EXPERIENCE
}

\author{
Marta Baran ${ }^{1}$ - ORCID: 0000-0002-7532-0215 \\ Dominik Nowakowski ${ }^{1}$ • ORCID: 0000-0002-3428-5089 \\ Janusz Lisiecki ${ }^{1}$ • ORCID: 0000-0003-3069-3453 \\ Sylwester Kłysz ${ }^{1,2} \bullet$ ORCID: 0000-0002-4521-4972
}

\begin{abstract}
${ }^{1}$ Air Force Institute of Technology, Księcia Bolesława 6, 01-494 Warsaw, Poland
${ }^{2}$ University of Warmia and Mazury in Olsztyn, Department of Technical Sciences, Michała Oczapowskiego 2, 10-719 Olsztyn, Poland

marta.baran@itwl.pl,dominik.nowakowski@itwl.pl, janusz.lisiecki@itwl.pl,sylwester.klysz@itwl.pl
\end{abstract}

\begin{abstract}
Laboratory for Materials Strength Testing (LMST) has been conducting accredited mechanical research for aviation from 2003. Among accredited procedures are e.g. low and high cycle fatigue tests, fracture toughness tests and fatigue crack growth rate tests. The main goal of them is obtaining materials constants and characteristics. However knowledge how to conduct these tests could be used also in other applications, for instance in the work on development of Structural Health Monitoring systems (SHM). When cracks propagate in a controlled way in laboratory conditions, it allows verifying the operation of a single sensor or a network of sensors.

In this paper, an overview of mechanical tests carried out at the Laboratory for Materials Strength Testing within Air Force Institute of Technology (AFIT) work on research and development of SHM systems is presented. Specimens prepared from materials such as aluminum alloys (among other withdrawn PZL-130 Orlik TC-II aircraft) and CFRP composite were tested under different mechanical loads, i.e., cycle and impact loads. In the presented research, both constant amplitude and spectrum loads were applied.
\end{abstract}

Keywords: BVID, CFRP, composite damage, fatigue crack, SHM

Article Category: Research Article

\section{INTRODUCTION}

Introducing new lightweight materials (e.g., composites) in the aircraft industry in conjunction with differences in assumed loads spectrum and real operational 
conditions are some of the reasons for developing Structural Health Monitoring (SHM) systems [1]. The Air Force Institute of Technology (AFIT) undertakes research and development of individual sensors and their systems [2] [3] [4]. These sensors are tested, among other, in a laboratory, under conditions of an existing damage or crack propagation.

One of the procedures included in the scope of LMST accreditation is method of studying fatigue crack growth rate that principles are described among others in international and domestic standards [5] [6] [7]. It allows for obtaining complete experimental relationships (Fig. 1) between the fatigue crack growth rate $d a / d N$ and a range of a stress intensity factor in a load cycle $\Delta K=K_{\max }-K_{\min }$ (or instead of $\Delta K$ : the maximum value of the stress intensity factor in the load cycle $K_{\max }$ ). A complete relationship is understood as the range from $K_{t h}$ value (the threshold stress intensity factor below which crack does not propagate) to $K_{c}$ value (above which a fast fracture begins).

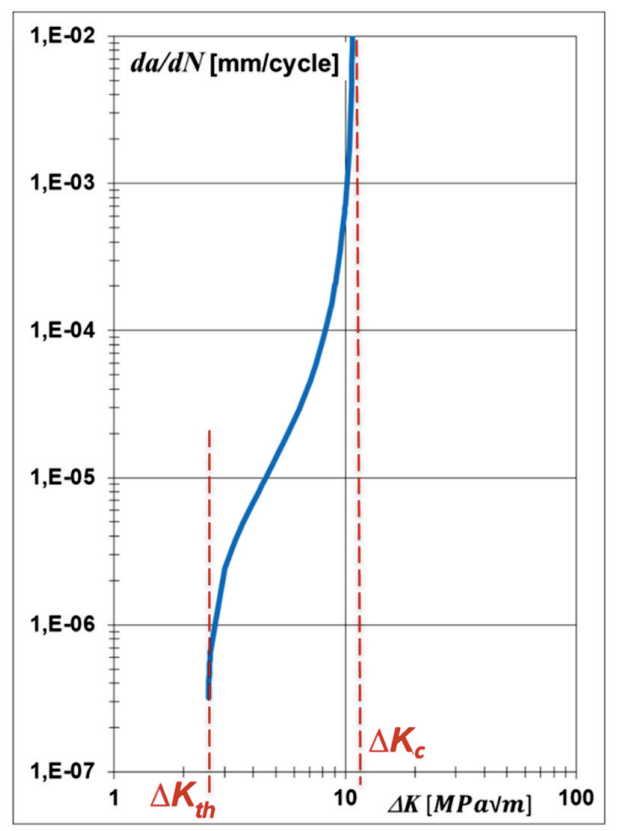

Fig. 1. A relationship between a fatigue crack growth rate $d a / d N$ and a range of a stress intensity factor $\Delta K$ in a load cycle.

The methods of conducting fatigue crack growth rate testing assume two possible control ways:

I. the range of the stress intensity factor in the load cycle $\Delta K$ is controlled,

II. a constant value of a force amplitude in the load cycle is controlled.

The test control in the first mode requires computing the current crack length value $a$ and stress intensity factor values $K_{\max }, K_{\min }$ in a continuous mode. Whereas test control in the second mode requires only maintaining defined values of maximum and minimum force $F_{\text {max }}, F_{\text {min }}$ in the load cycle.

In the case of crack propagation in SHM sensors tests carried out at the Laboratory for Materials Strength Testing AFIT, the goal was producing possibly long stable cracks often in specimens with nonstandard geometry. Considering that - better (easier and enough) way of test control is the abovementioned second mode. 
Relationships between the crack length $a$ and the number of cycles $N$ for two values of stress $\sigma$ in tests carried out under the condition of constant amplitude were shown in Fig. 2. Crack length $a$ increasing involves fatigue crack growth rate $d a / d N$ increasing:

$$
(d a / d N)_{a_{j}}^{\sigma_{1}}>(d a / d N)_{a_{i}}^{\sigma_{1}},
$$

which leads to unstable crack propagation and the fast fracture. Similarly, increasing stress results in increasing fatigue crack growth rate:

$$
(d a / d N)_{a_{j}}^{\sigma_{2}}>(d a / d N)_{a_{j}}^{\sigma_{1}}
$$

The described above relationships were unusually used during SHM sensors tests to modify the fatigue crack growth rate in order to obtain as large geometrically fatigue cracks in metals as possible.

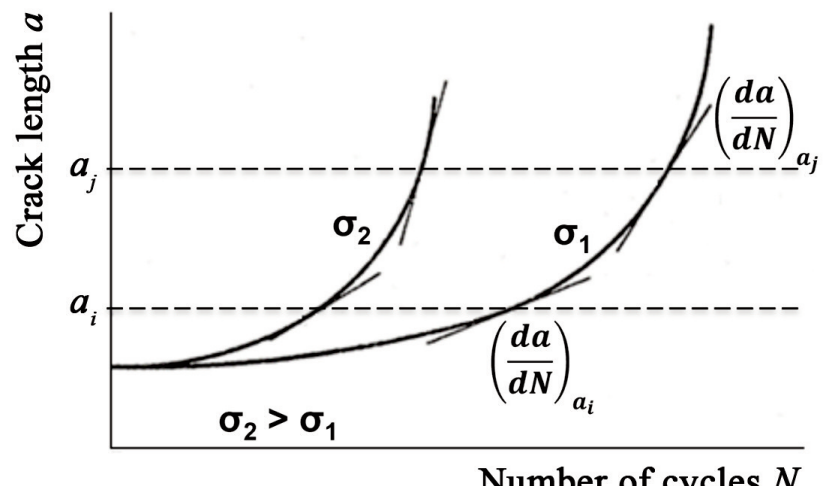

Fig. 2. Relationships between crack length $a$ and number of cycles $N$ for two stress values.

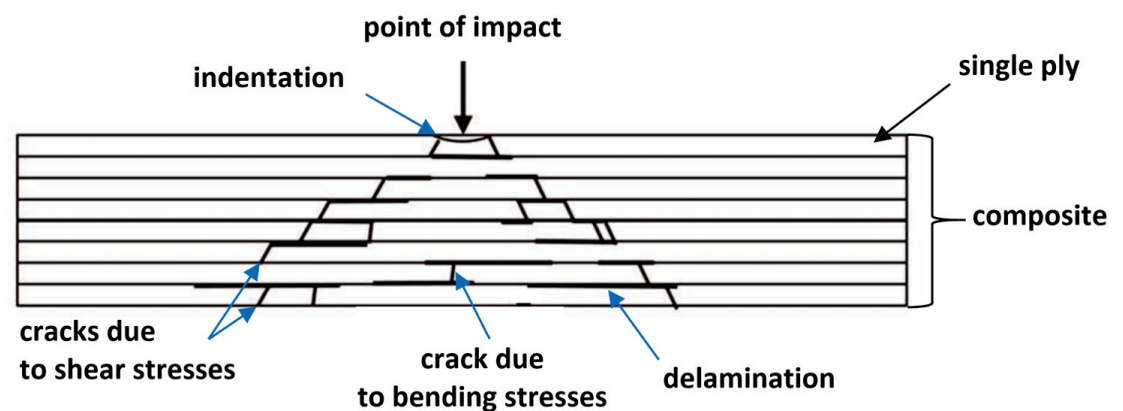

Fig. 3. A barely visible impact damage (BVID) in a composite structure [8].

For composites mentioned at the beginning of this paper, different types of load could pose a threat, namely barely visible impact damage (BVID). These specific cone-shaped damages occur as a result of low energy impacts (Fig. 3). Despite of only the small indentation from the impact side, damage increases with the depth. BVIDs are particularly dangerous because they are un- or poorly-detectible with the naked eye. BVID detection often is possible only with using non-destructive testing methods. 
In the following parts of this paper selected SHM sensors tests in presence of both cracks in aluminum alloys and BVID in the composite structure are presented.

\section{MECHANICAL TESTS APPLIED TO SHM SYSTEMS - SELECTED SPECIMENS}

1. The crack growth under the quasi-constant load

The research object was a specimen taken from a wing skin of the withdrawn PZL-130 Orlik TC-II aircraft. The specimen was in the form of an aluminum alloy sheet with two longerons (Fig. 4). The mechanical notch was cut on the one edge of the specimen, between the longerons and parallel to them (Fig. 4c). The placement of the notch was such that an expected crack propagation path went through following SHM sensors (like resistive ladder and eddy current sensors - Fig. 4c) or through an area of their work (PZT transducers mounted on the top and near the bottom longeron - Fig. 4).

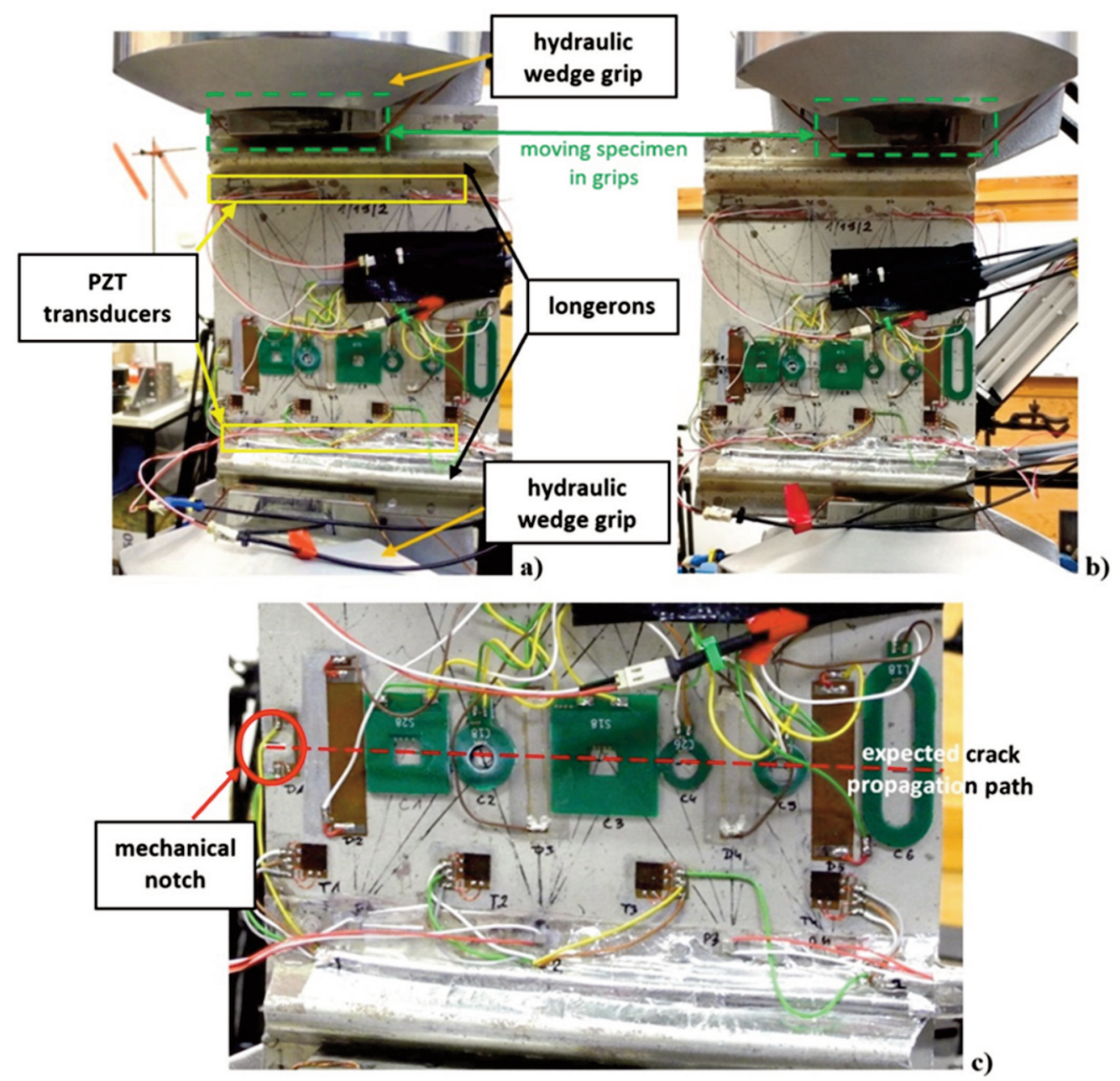

Fig. 4. The specimen installed in the testing machine. 
The test was performed using a servohydraulic testing machine (MTS test system, model 322.31) and manufacturer's software (MultiPurpose TestWare - Fig. 5). The test was defined by the following parameters:

- control signal - force,

- shape of control signal - sinusoidal wave,

- maximum and minimum force values in the load cycle (minimum value was constant throughout the test),

- load frequency.

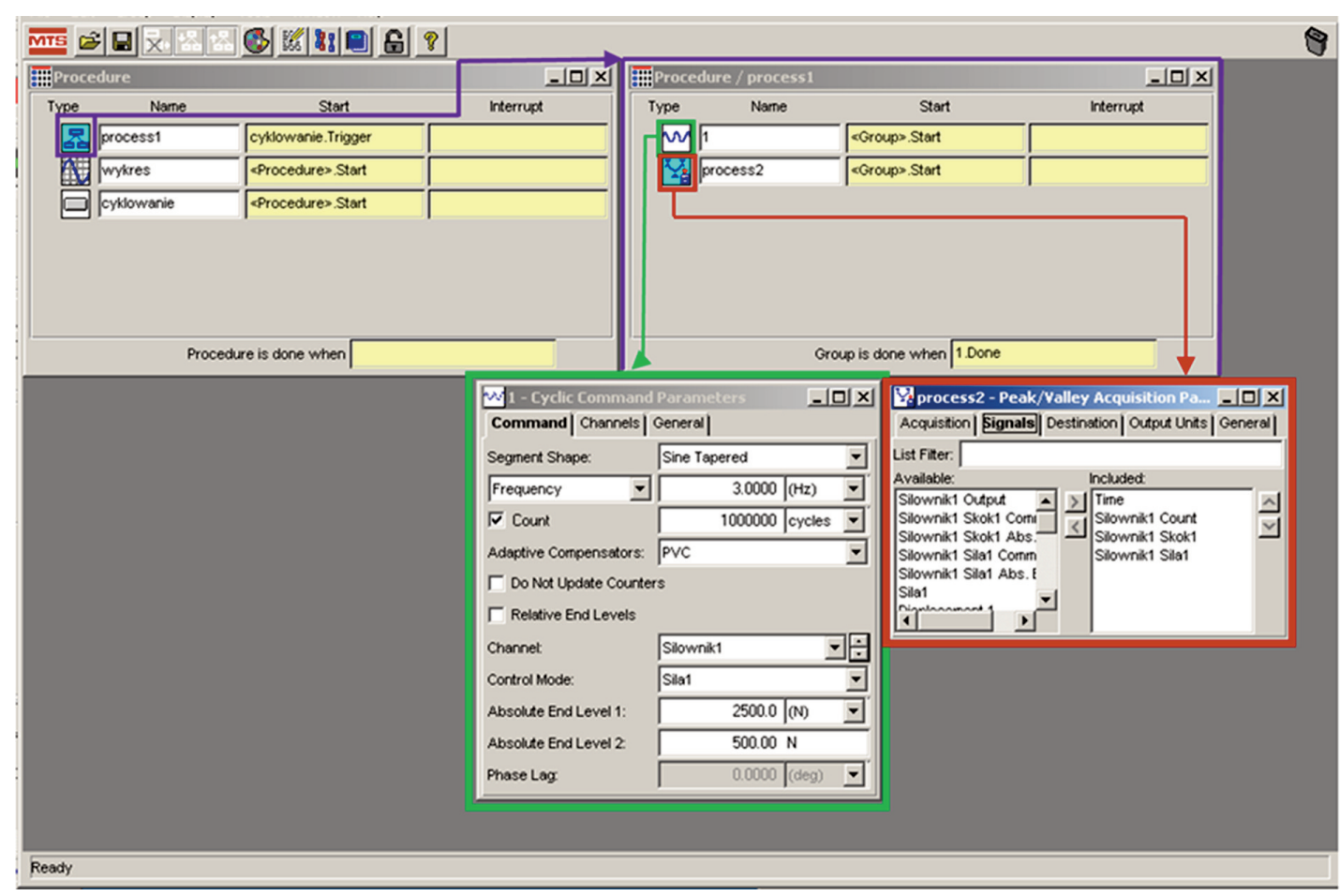

Fig. 5. The view of the test control application.

Changes in the control signal are shown in Fig. 6a, which presents maximum and minimum force values in the following cycles. Maximum and minimum values of the actuator displacement in the following cycles are presented in Fig. 6b. It is worth noticing that there was good correlation between the actuator displacement and the crack length. Taking it into account, the actuator displacement was one of the factors which allow to evaluate necessity of modifying test parameters (together with visual inspection of the specimen surface and a visual estimation of the crack length).

The test started from a safe level of load, after which maximum force in cycle was gradually increased until a crack initiated and a crack was observed on the specimen surface (about several thousands of cycles). That moment is marked by the red dotted line in Figs. 6a and 6b.

The crack propagation was considered stable between 20 and 40 thousand of cycles, therefore force value was not changed in that range of cycles. 

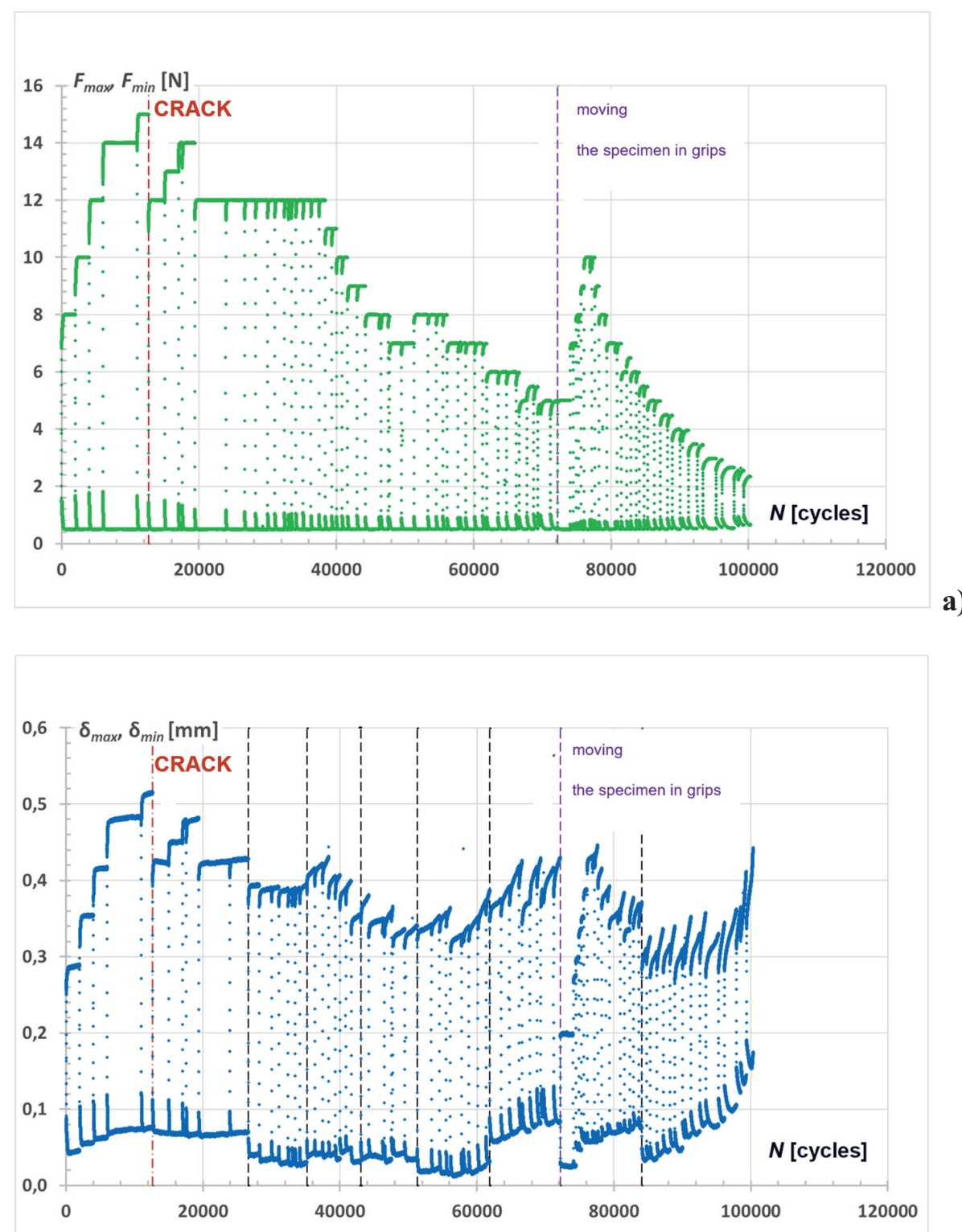

a)

b)

Fig. 6. Maximum and minimum:

a) force in load cycles $F_{\max }, F_{\min }$ versus number of cycles in test $N$, b) displacement in load cycles $\delta_{\max }, \delta_{\min }$ versus number of cycles in test $N$.

The crack growth rate near 40 thousand cycles was big enough to make it necessary to decrease the maximum force in load cycle. It was equal to changing the propagation curve in Fig. 7 from $\sigma_{2}$ to $\sigma_{1}$.

That method was no longer sufficient after slightly over 70 thousand cycles. In order to prevent fast fracturing of the specimens, crack was artificially shortened, which is visible in Fig. 7, by transition from point $(d a / d N)_{a_{j}}$ to point $(d a / d N)_{a_{i}}$. In practice this meant moving the specimen in the grips (Fig. 4a and Fig. 4b) perpendicularly to the specimen's axis in such a way that the crack tip was closer to grips' edges and the specimen load axis. 


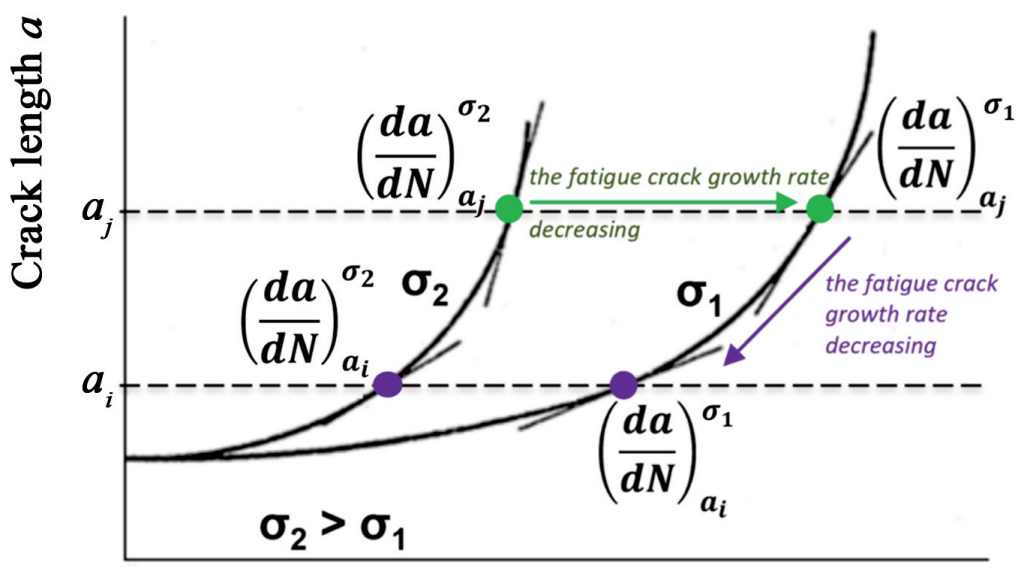

Number of cycles $N$

Fig. 7. Relationship between crack length $a$ and number of load cycles $N$ for two levels of stresses $\sigma_{2}>\sigma_{1}$.

That allowed the operators to slow down the test and recover control of the crack growth rate by changing force amplitude, permitting damaging the specimen in a controlled way and registration of PZT network signals in a larger range of crack length in the specimen structure - and thus better test the sensor network.

2. The crack growth under the spectrum load

The second presented object was a specimen made of aluminum alloy (Al 2024-T4) with a geometry shown in Fig. 8, was PZL-130 Orlik TC-II aircraft spar flange geometry representation. On both sides of the hole (parallel to the specimen axis) resistive ladder sensors were installed (Fig. 10c).

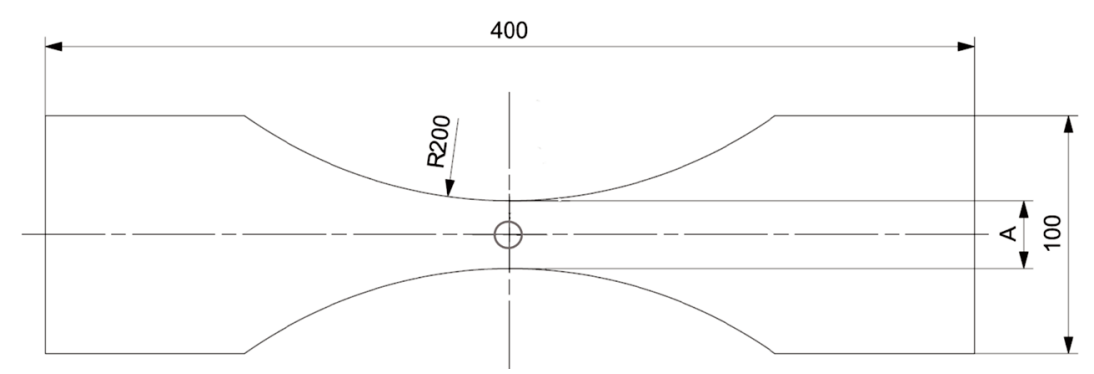

Fig. 8. The geometry of the specimen.

The test was performed using a servohydraulic testing machine (MTS test system, model 322.31) and the manufacturer's software (MultiPurpose TestWare with Profile option - Fig. 9). The test was defined by the following parameters:

- control signal - force,

- shape of control signal - sinusoidal wave,

- maximum and minimum forces and frequency value in each load cycle. 


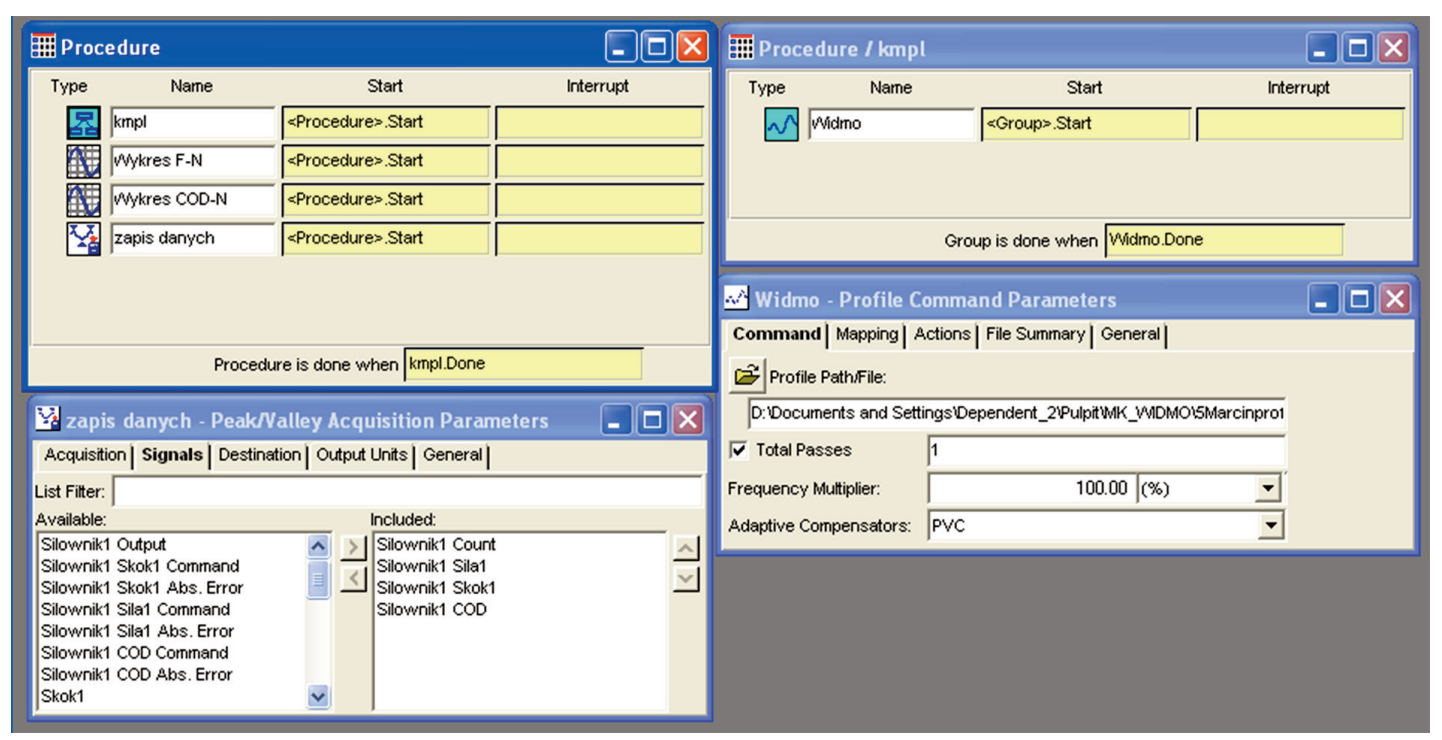

Fig. 9. The view of test control application.

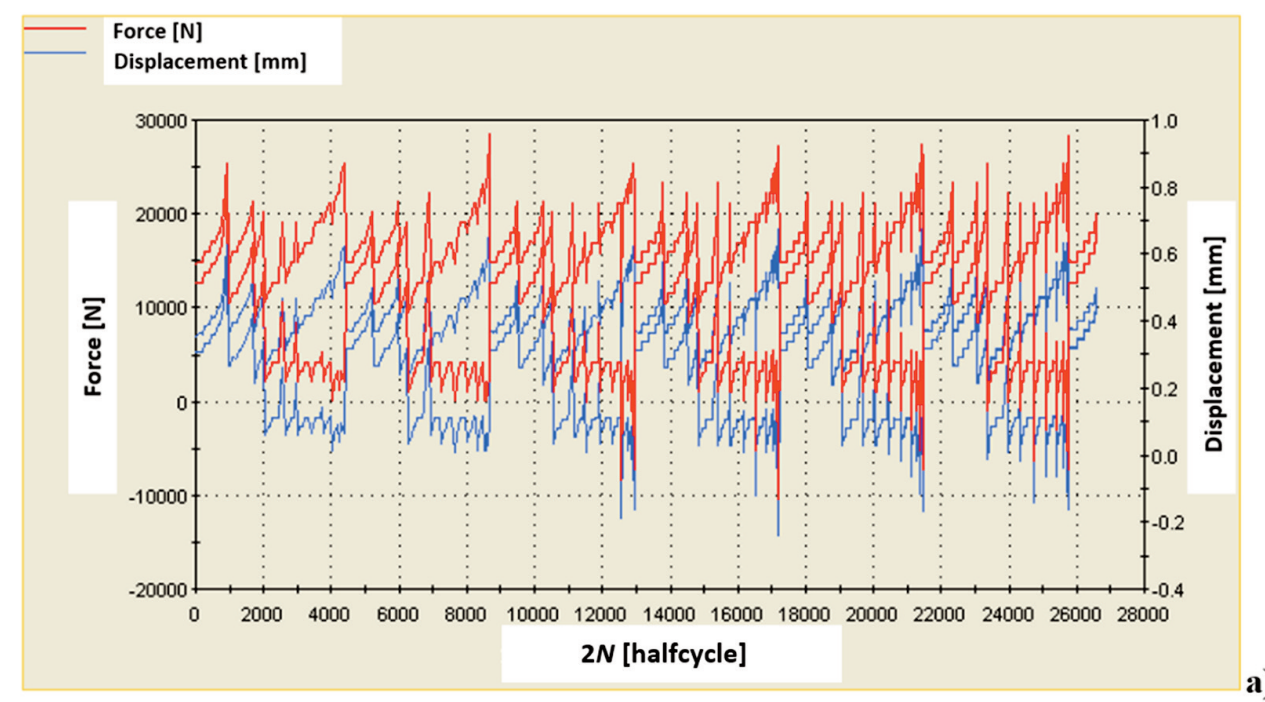

a)
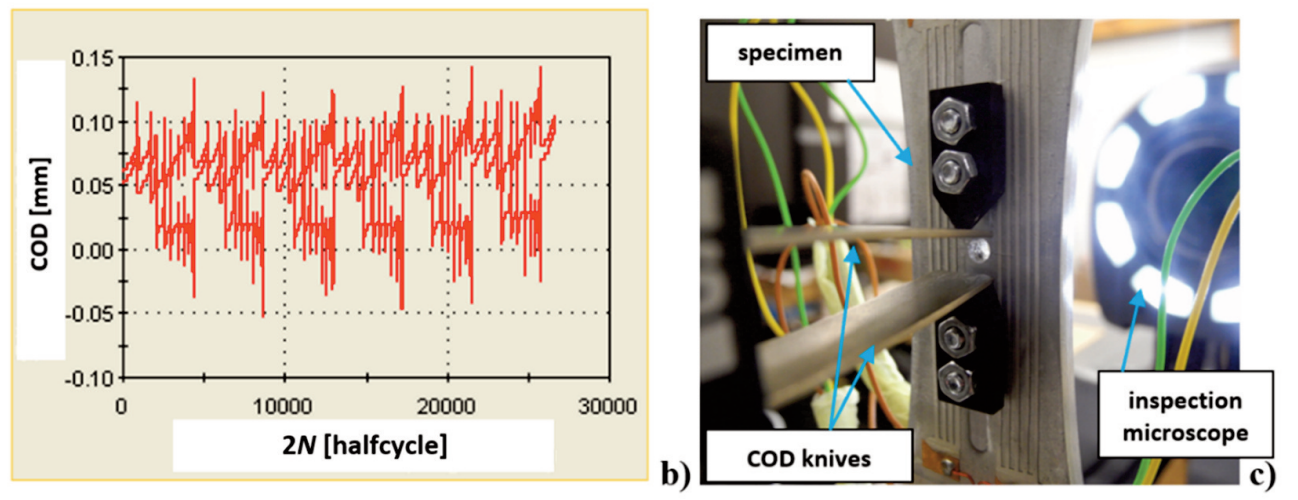

Fig. 10. Relationships between: a) maximum, minimum forces $F_{\max }, F_{\min }$ in a load cycle and a doubled number of halfcycles $(2 N)$; b) maximum, minimum actuator displacement $\delta_{\text {max }}, \delta_{\text {min }}$ in a load cycle and a doubled number of halfcycles $(2 N)$; c) the specimen installed in the testing machine. 
The control signal during the test is shown in Fig. 10a by the red line. It presents maximum and minimum force values in following cycles. Maximum and minimum values of the actuator displacement in following cycles are presented in the same figure by the blue line. The additional instrumentation was an extensometer COD attached to the specimen as in Fig. 10c, whose indications are presented in Fig. 10b.

Compared to the specimen considered in the first point (the crack growth under the quasi-constant load), observation of the correlation between the actuator displacement or COD indication and the crack length was much more difficult. In that case both the actuator displacement and COD indications were not easy to use factors for crack propagation control. In that test the crack propagation control was obtained by scaling all forces in the profile file based on the visual observation of the specimen surface using an inspection microscope (Fig. 10c).

Scaling forces in the profile file allowed obtaining crack length close to the last strands in the resistive ladder sensors.

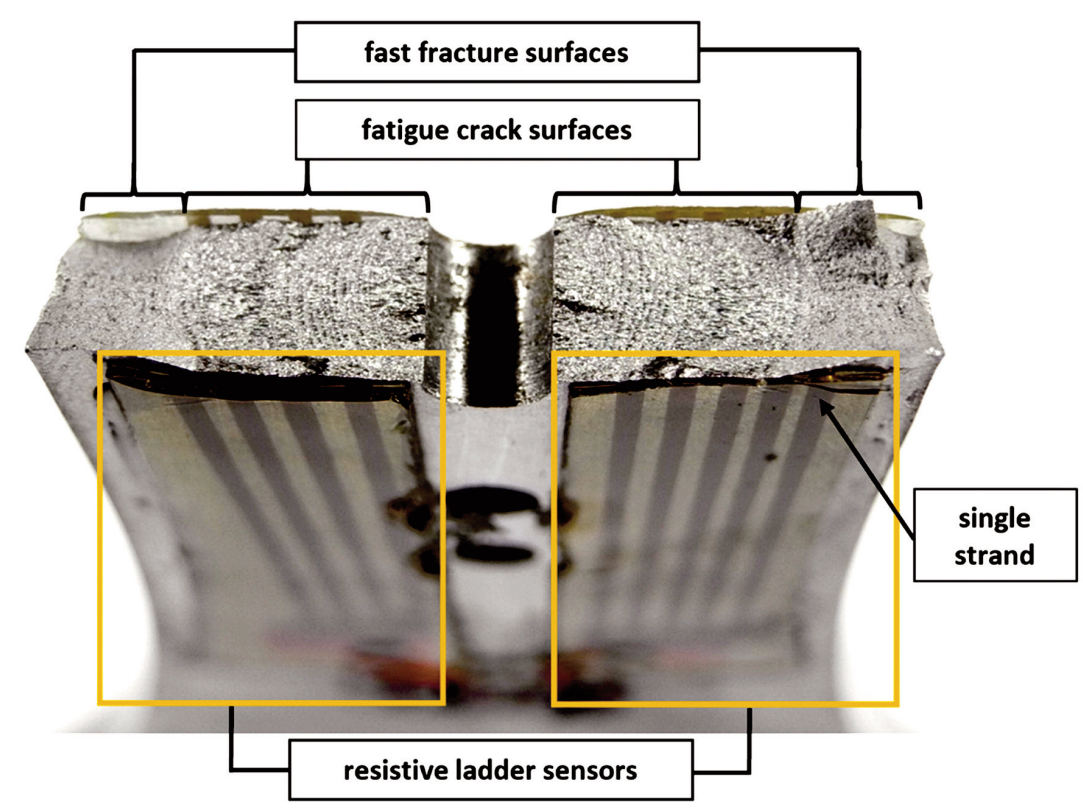

Fig. 11. A fracture surface after test.

3. The barely visible impact damage in the composite structure

Last but not least, out of the three specimens presented differs significantly from the other two both under the condition of material and load kind. The specimen was made of carbon fiber reinforced composite with the epoxy resin matrix. It was first subjected to impact load and then compressed in order to obtain the value of residual strength.

The specimen was cut out using the water jet method from a panel made of prepreg composed of E722 epoxy resin and ultra-high strength fibers using the technology of a vacuum bag in an autoclave. The panel and hence the specimen were multidirectional CFRP laminate consisting of 24 plies. The geometry of the specimen is shown in Fig. 12. The thickness of the specimen is not indicated because it was dependent on a number of prepreg plies. 


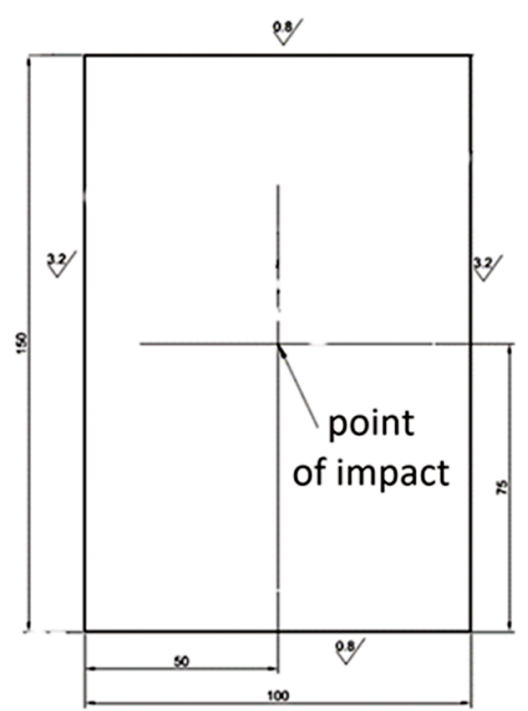

Fig. 12. Geometry of CFRP specimen [10].

Before damage was introduced to it, the specimen underwent non-destructive testing using the flash thermography method. Fig. 13 shows the thermograms made on both sides of the specimen. Good quality of composite can be noticed. There are no delaminations or pores. PZT transducers which were installed prior to the non-destructive test are clearly visible. Lighter stripes visible in the thermogram indicate where pieces of tapes were used to protect PZT transducers during storage and transportation.

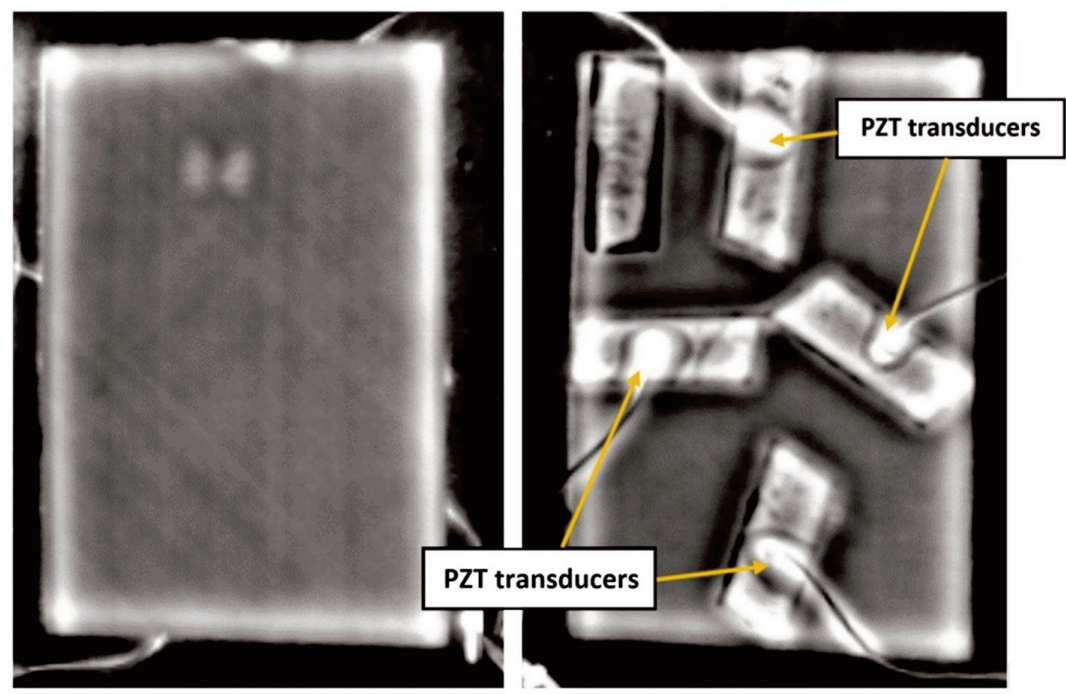

Fig. 13. Thermograms - CFRP specimen with PZT transducers installed before drop-weight impact.

Damage introducing was performed according to the ASTM D7136/D7136M-15 standard [10]. Rigid impact support fixture with the CFRP specimen placed in is shown in Fig. 14a. An impact energy value $E$ was assumed regardless of standard [10] and equal to $15 \mathrm{~J}$. Drop-height to produce this energy $H$ was calculated using the following equation: 


$$
H=\frac{E}{m \cdot g}
$$

where $E$ - potential energy of impactor prior to drop,

$H$ - drop-height of impactor,

$m$ - mass of impactor (Fig. 14b),

$g$ - gravitational acceleration.
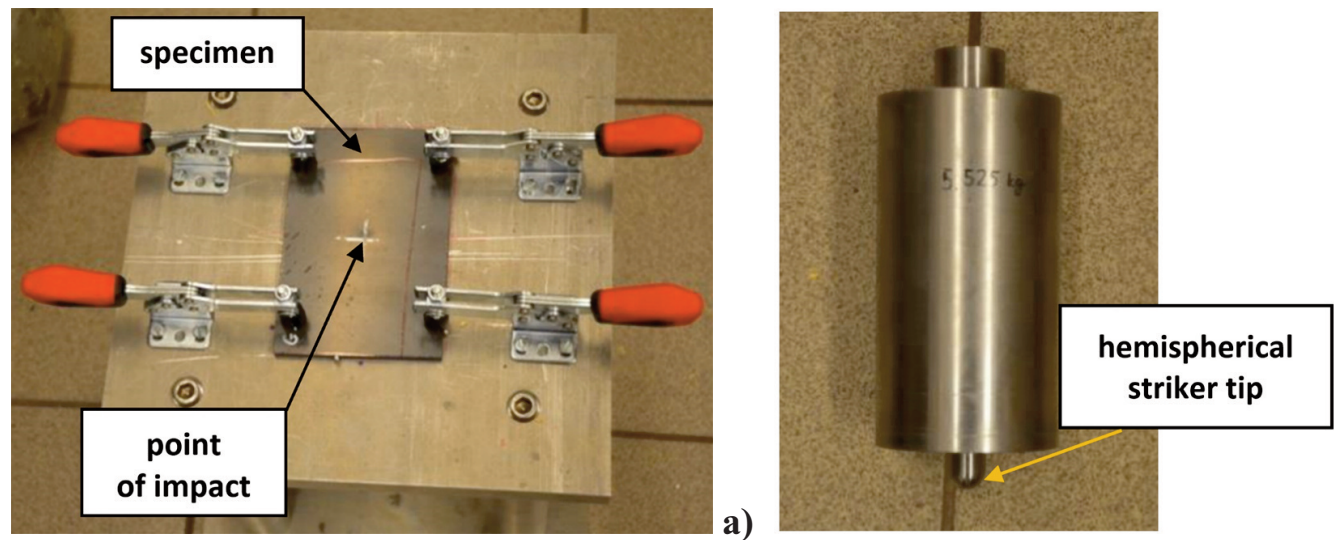

a)

b)

Fig. 14. a) Specimen placed in impact support fixture, b) impactor (complied with [10]).
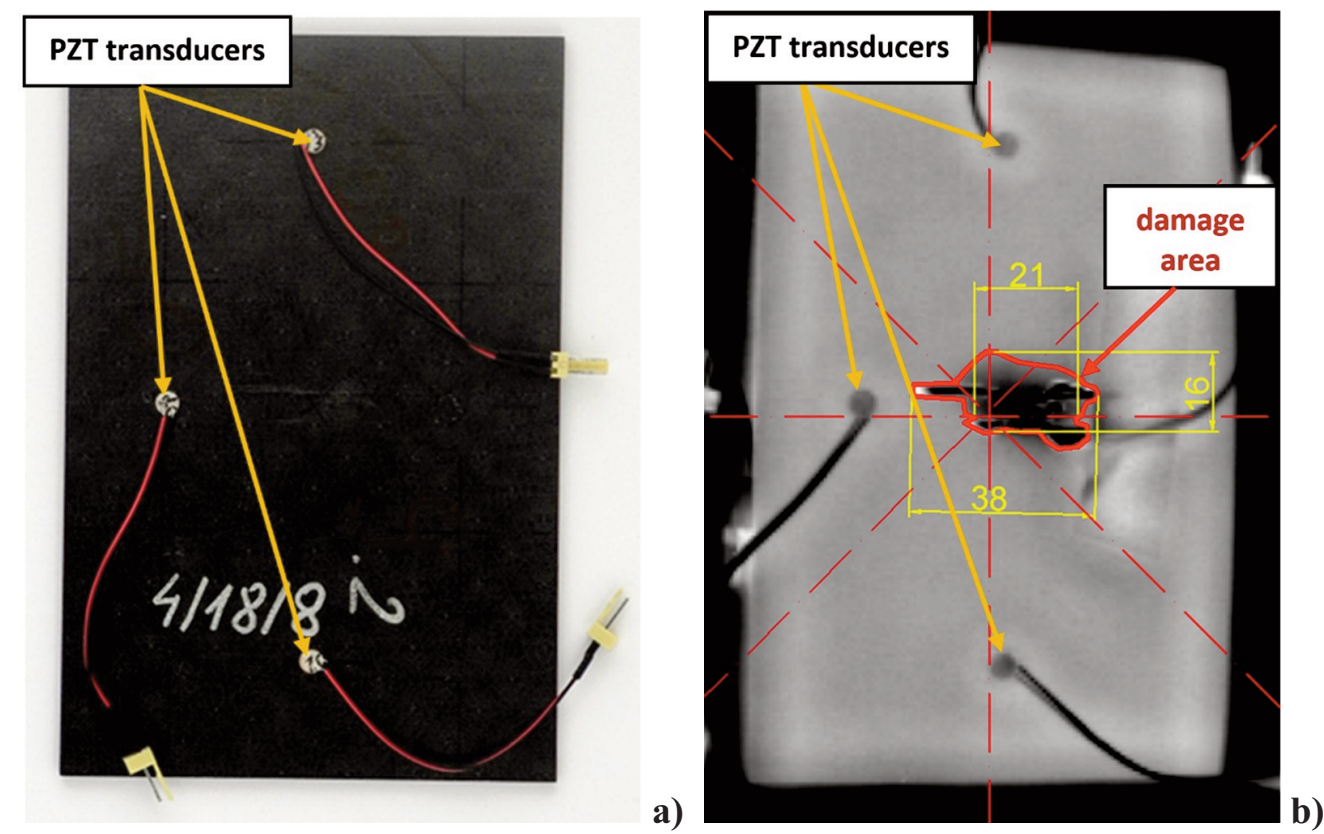

Fig. 15 CFRP specimen with PZT transducers installed after drop-weight impact

a) photo of the side opposite to the impact surface,

b) thermogram with dimensioning of damage area.

The photo of the specimen and its thermogram are presented in Fig. 15. Dimensioning of the damage area apparent in Fig. 15b was performed according to the ASTM D7136/D7136M-15 standard [10] and relates to the biggest area of damage which was visible. 
It is worth noticing that impact of the hemispherical striker tip (Fig. 14b) with diameter of several millimeters caused damage whose maximum dimension equaled to $38 \mathrm{~mm}$.

In Fig. 15 only three PZT transducers are marked whereas in Fig. 13 there are four. The reason of this difference was a falling off one of the transducers during damage introducing.

\section{SUMMARY}

This paper presents a brief overview of mechanical tests carried out as part of research and development of Structural Health Monitoring systems at the Laboratory for Material Strength Testing AFIT. These tests allowed to verify working individual sensors and their network on cases of cracks and damage similar to these occurring on aircraft.

Three cases were selected among the activity of the laboratory to show the greatest possible variety of used loads and materials, i.e.

- in terms of loads:

- the quasi-constant amplitude test, where value of force amplitude was used to control fatigue crack growth rate,

- the spectrum load test, where amplitude was scaled to control crack growth rate,

- the impact load used in order to obtain barely visible impact damage (BVID),

- in terms of materials:

- the aluminum alloy (also from the withdrawn component),

- the carbon fiber reinforced composite (CFRP).

\section{REFERENCES}

[1] Dragan, K., Dziendzikowski, M., Kurnyta, A. and Kowalczyk, K. (2020). Perspective of Structural Health Monitoring for Military Aviation in Poland. ICAF 2019, Lecture Notes in Mechanical Engineering, Niepokolczycki A. and Komorowski J. (Eds.), pp. 1065-1081.

[2] Dziendzikowski, M., Niedbala, P., Kurnyta, A., Kowalczyk, K. and Dragan, K. (2018). Structural Health Monitoring of a Composite Panel Based on PZT Sensors and a Transfer Impedance Framework. Sensors, 18(5), 1521.

https://doi.org/10.3390/s18051521

[3] Kowalczyk, K., Dziendzikowski, M., Kurnyta, A., Niedbala, P. and Dragan, K. (2020). Application of RLC Filters and Analog Circuits for Increasing Information Bandwidth of Channels of Data Acquisition Units. ICAF 2019, Lecture Notes in Mechanical Engineering, Niepokolczycki A. and Komorowski J. (Eds.), pp. 956-965.

[4] Kurnyta, A., Dziendzikowski, M., Dragan, K. and Leski, A. (2014). Approach to Health Monitoring of an Aircraft Structure with Resistive Ladder Sensors During Full Scale Fatigue Test. 7th European Workshop on Structural Health Monitoring, July 8-11, 2014. La Cité, Nantes, France. 
[5] ASTM E647-15: Standard Test Method for Measurement of Fatigue Crack Growth Rates.

[6] ISO 12108:2018 Metallic materials — Fatigue testing — Fatigue crack growth method.

[7] PN-84/H-04333: Metoda badania wzrostu pęknięcia zmęczeniowego przy stałej amplitudzie obciążenia.

[8] Wronkowicz-Katunin, A., Katunin, A. and Dragan, K. (2019). Reconstruction of Barely Visible Impact Damage in Composite Structures Based on Non-Destructive Evaluation Results. Sensors, 19(21), 4629. https://doi.org/10.3390/s19214629.

[9] Wyrzykowski, J., Pleszakow, E. and Sieniawski, J. (1999). Odkształcanie i pękanie metali. WNT, Warszawa. ISBN: 83-204-2341-4.

[10] ASTM D7136/D7136M-15. Standard Test Method for Measuring the Damage Resistance of a Fiber-Reinforced Polymer Matrix Composite to a Drop-Weight Impact Event.

[11] Baran, M. and Synaszko, P. (2018). Compression After Impact Research, Laboratory for Materials Strength Testing Report No. SP-88/31/2018. AFIT Library. 